\title{
Toxicon
}

Toxicon 40 (2002) 1129-1134

www.elsevier.com/locate/toxicon

\section{Removal of cyanobacterial microcystin-LR by ferrate oxidation-coagulation}

\author{
Bao-Ling Yuan ${ }^{\mathrm{a}, *}$, Jiu-Hui Qu ${ }^{\mathrm{a}}$, Ming-Lai Fu ${ }^{\mathrm{b}}$ \\ ${ }^{a}$ State Key Laboratory of Environmental Aquatic Chemistry, Research Center for Eco-Environmental Sciences, \\ Chinese Academy of Sciences, Beijing 100085, People's Republic of China \\ ${ }^{\mathrm{b}}$ State Key Laboratory of Structural Chemistry, Fujian Institute of Research on the Structure of Matter, \\ Chinese Academy of Sciences, Fuzhou 350002, People's Republic of China
}

Received 27 November 2001; accepted 16 March 2002

\begin{abstract}
In this study, the effect of a multiple function reagent-ferrate on the removal of microcystins-LR (MCLR) from freeze-dried Planktothrix sp. was investigated. The toxin was easily decomposed by oxidation with ferrate, and the removal efficiency depended on the dosage of ferrate, $\mathrm{pH}$, and contact time. Simultaneously the reduction product $\mathrm{Fe}(\mathrm{OH})_{3}$ after ferrate oxidation could flocculate the organic compounds so that 50\% TOC removal of the extract was reached. The low residual iron reflected the excellent results of coagulation and could meet the standard of drinking water. Analysis of the treated cyanobacterial extracts by high-performance liquid chromatograph, monitoring absorbance at 210 and $238 \mathrm{~nm}$, suggested that the heptapeptide ring of MCLR and its Adda group had been opened or modified, respectively. So ferrate treatment may be an effective and practical method for the removal of cyanobacterial peptide toxins from eutrophic waters, especially which hold high total organic carbon. (C) 2002 Elsevier Science Ltd. All rights reserved.
\end{abstract}

Keywords: Planktothrix sp; Microcystin-LR; Ferrate; Oxidation; Coagulation

\section{Introduction}

The increasing eutrophication of fresh waters many of which include drinking water reservoirs by human activity has increased the occurrence and intensity of cyanobacterial blooms (Sivonen et al., 1990) and approximately 50\% of them are known to be toxic (Codd, 1995). The most commonly occurring toxins produced by cyanobacteria are microcystins. Microcystin, a cyclic hepatotoxin produced by some freshwater cyanobacteria such as Microcystis, Planktothrix, and Anabaena, causes potent hepatotoxicity and tumor-promoting activity in animal and human through inhibition of proteinphosphatases 1 and 2A (Eriksson et al., 1990). Microcystin-LR contains the amino acid 3amino-9methoxy-2,6,8-trimethyl-10-phenyldeca-4,6-dienoic acid (Adda), with leucine (L) and arginine (R) in the variable positions (Fig. 1). The potential for these toxins to

\footnotetext{
* Corresponding author. Tel.: +86-10-62849160; fax: +86-1062923547.

E-mail address: yuanbl@ hotmail.com (B.-L. Yuan).
}

impact adversely on human health requires that these toxins be removed from water supplies prior to use.

Many strategies for the removal of cyanobacterial toxins from water have been investigated. The conventional water treatment processes have so far failed to remove them effectively (Himberg et al., 1989). Both powdered and granular activated carbon has shown only limited efficacy and are expensive (Lambert et al., 1996). Biological methods typically require a reaction time of hours to days and are thus not viable (Angeline et al., 1995). Rositano et al. (1998) observed a reduction in purified microcystin-LR to below detection limits following ozone treatment. However, the study also found the destruction of the hepatotoxin to be $\mathrm{pH}$ dependent, with alkaline $\mathrm{pH}$ values usually experienced during a bloom (7.3-9.9), less effective. Usually, raw water is treated for drinking water purpose by the process including chlorination. Treatment using chlorination requires high doses and long contact times, and may produce carcinogenic substances such as trihalomethane (Bellar et al., 1974) and other mutagens (Kronberg and Vartianen, 1988). So we adapted ferrate as a combined oxidant-coagulant to remove microcystin from raw water. 


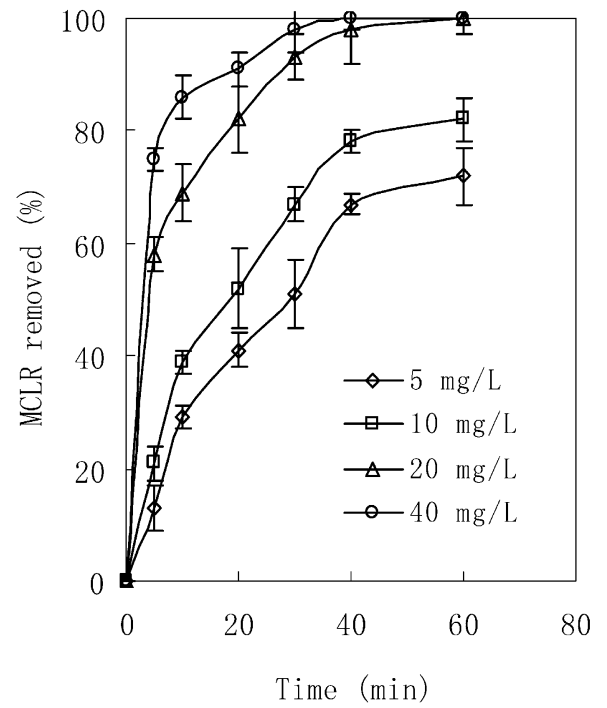

Fig. 1. Decomposition of microcystin-LR by ferrate at various doses. Bars represent $1 \mathrm{SD}(n=2)$.

Ferrate, the salt of the iron(VI) oxyanion $\mathrm{FeO}_{4}^{2-}$, is a powerful oxidant throughout the $\mathrm{pH}$ scale, and decomposes in aqueous solution generating $\mathrm{Fe}^{3+}$, hydroxide ion, and molecular oxygen. Because of the dual oxidation-coagulation functions, Gilbert et al. (1976) have shown that potassium ferrate is an effective oxidant of organic matter such as phenol and allylbenzene. It is also proved that ferrate did not generate by-products which will cause toxicity or mutagenicity that are harmful to humans health and environment as chlorination and ozone treatment (De Luca et al., 1983). Furthermore, a single reagent that combines oxidation and coagulation obviously has advantage over using chlorine or ozone or peroxide for oxidation and then using alum or iron for coagulation. For its special ability in water purification, ferrate, as an oxidant-coagulant, may be useful to eliminate microcystin-LR and a study was undertaken.

In this study, we investigated in detail the decomposition of microcystin-LR by ferrate at its different dosage, $\mathrm{pH}$ scale, and reaction time. SPE and HPLC were used in this work for concentrating and analyzing the toxin.

\section{Materials and methods}

\subsection{Equipment}

Yamato Freeze-dryer DC 41 (USA) was used for freeze-drying cyanobacteria. Retsch sonifier (USA) and Beckman J2-Hs refrigerated superspeed centrifuge (USA) were used for the extraction of the freeze-dried cyanobacterial material. Visiprep ${ }^{\mathrm{TM}}$ DL solid phase extraction equipment (Supelco, USA), Pyrex filter (Millipore, USA) and $3 \mathrm{ml} 500 \mathrm{mg}$ Supelclean LC18 solid phase extraction cartridge (Supelco, USA) were utilized for the concentration of microcystin-LR.

\section{2. $H P L C$}

A high performance liquid chromatograph consisted of a Shimadzu (Kyoto, Japan) LC-10A pump coupled to a SPDM10A photodiode array detector system. Separation was accomplished under a reversed-phase isocratic condition with a Microsorb ${ }^{\mathrm{TM}} \mathrm{C} 18$ column $(5 \mu \mathrm{m}, 150 \mathrm{~mm} \times 4.6 \mathrm{~mm}$ i.d., Rainin Instrument Company, Inc., MA, USA). The mobile phase used for the analysis, was acetonitrile: $0.01 \mathrm{~mol} / \mathrm{l}$ ammonium acetate $(\mathrm{pH}$ 6.8) (32:68) at a flow rate of $1 \mathrm{ml} / \mathrm{min}$.

\subsection{Materials}

Culture of Planktothrix sp. (FACHB-595) was obtained from the Culture Collection of Algae, Wuhan Institute of Hydrobiology, China. Microcystin-LR was isolated and purified from cells blooms which were purely cultured in laboratory. Standard microcystin-LR was purchased from Sigma Chemical Co. (St Louis, MO, USA).

Potassium ferrate $\left(\mathrm{K}_{2} \mathrm{FeO}_{4}\right)$ was synthesized according to the method (Schreyer et al., 1953) which includes hypochlorite oxidation of ferric nitrate in a strong alkaline solution. Because the solubility of $\mathrm{K}_{2} \mathrm{FeO}_{4}$ is less than that of $\mathrm{Na}_{2} \mathrm{FeO}_{4}$, potassium ferrate is precipitated by the addition of potassium hydroxide to the $\mathrm{Na}_{2} \mathrm{FeO}_{4}$ solution. The potassium ferrate was then filtered, washed by isopropanol, ether, benzene in series, dried, and analyzed for its purity and concentration by the method of chromite oxidation (Schreyer et al., 1953). In all experiments purity of ferrate is greater than $90 \%$.

\subsection{Microcystin-LR extraction}

Dried cyanobacteria, taken from a Planktothrix sp. bloom possessing naturally high levels of microcystin-LR, was suspended in distilled water and sonicated three times with an ultrasonic cell disrupter for $30 \mathrm{~s}$. After cell disruption, the solution was centrifuged at $15000 \times g$ for $20 \mathrm{~min}$ at $4{ }^{\circ} \mathrm{C}$ and the supernatant was removed and refrigerated. The earlier procedure was repeated after resuspending the pellets remaining in the centrifuge tubes with additional distilled water and the second supernatant was added to the previous extraction mixture. The final blue extract was stored at $-20{ }^{\circ} \mathrm{C}$ until required.

\subsection{Ferrate treatment of freeze-dried cyanobacteria extract in distilled water}

The blue extract $(50 \mathrm{ml})$ was added to approx. $240 \mathrm{ml}$ distilled water at room temperature, the required dose of aqueous ferrate solution was added and the solution made up to $300 \mathrm{ml}$ with distilled water. The solutions were left to stand for $30 \mathrm{~min}$ with occasional stirring until sodium 


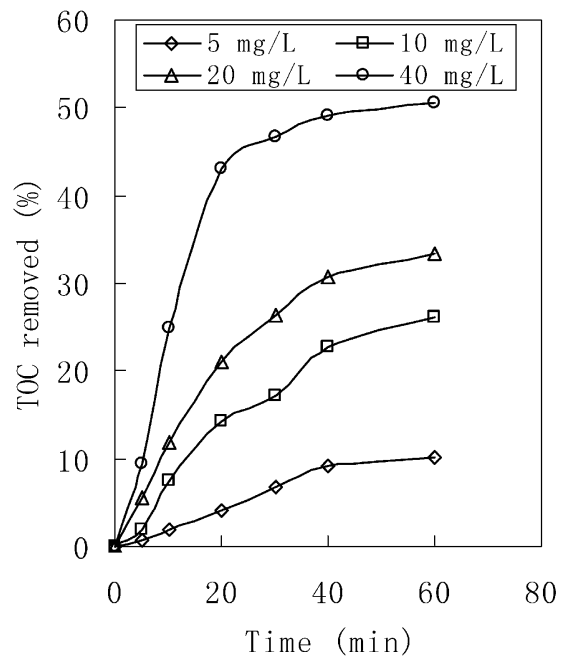

Fig. 2. TOC removal by ferrate oxidation-coagulation with different doses.

sulphite was added to end the reaction then allowed to settle for $30 \mathrm{~min}$. All experiments were run in duplicate.

\subsection{HPLC analysis of treated extract}

The supernatant for toxin analysis was filtered through a Millpore filter and adjusted to $\mathrm{pH}$ 6-7 with $0.1 \mathrm{M}$ hydrochloric acid or sodium hydroxide if not already within this range. Toxin was extracted from water samples using a Sulpeco C18 $500 \mathrm{mg}$ solid phase extraction cartridge. The cartridge was primed with methanol $(10 \mathrm{ml})$, followed by distilled water $(15 \mathrm{ml})$ after which the sample was passed through (flow rate $10 \mathrm{ml} / \mathrm{min}$ ) by vacuum suction. The cartridge was washed successively with distilled water $(10 \mathrm{ml}), 10 \%$ methanol $(10 \mathrm{ml})$ and $20 \%$ methanol $(5 \mathrm{ml})$, and then dried by drawing air through for $2 \mathrm{~min}$. The toxin was eluted using three bed volume of methanol at common pressure. The extract was evaporated to dryness under a stream of nitrogen, and the residue was taken up in $1 \mathrm{ml}$ of distilled water. The extract was analyzed by reverse phase HPLC using photodiode array detection at $238 \mathrm{~nm}$ injecting $20 \mu \mathrm{l}$ volumes into an analytical column. The mobile phase was $32 \%$ acetonitrile: $0.01 \mathrm{~mol} / \mathrm{l}$ ammonium acetate $(\mathrm{pH} 6.8)$ at a flow rate of $1 \mathrm{ml} / \mathrm{min}$. Determination of the extent of organic compounds adsorption on $\mathrm{Fe}(\mathrm{OH})_{3}$ was measured via TOC measurements using Apollo 9000 (Dohrmann, USA). The amount of iron remaining in the supernatant was measured with a polarized Zeeman atomic absorption spectrometer (Hitachi, Z-6100).

\section{Results and discussion}

\subsection{Effect of ferrate treatment on microcystin-LR removal}

The decomposition of microcystin-LR (MCLR) by ferrate

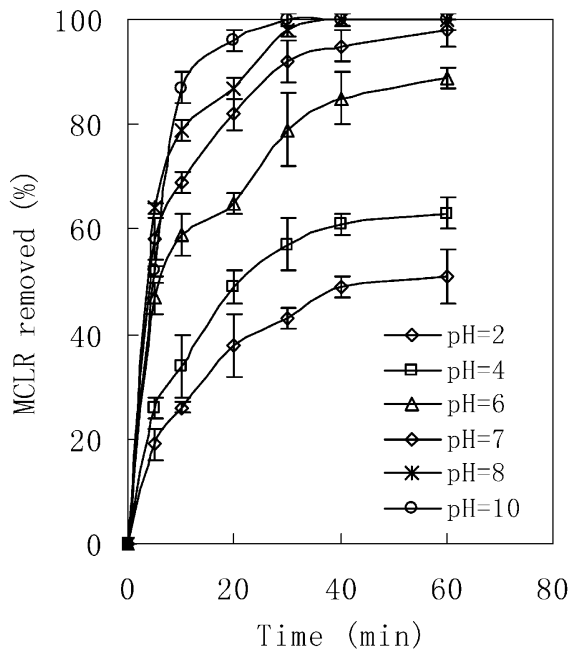

Fig. 3. Decomposition of microcystin-LR by ferrate at various $\mathrm{pH}$. Bars represent $1 \mathrm{SD}(n=2)$.

at different reaction times was investigated. Microcystin-LR in water was oxidized by the addition of different amounts of ferrate. The reduction of ferrate in water is caused by oxygen radicals and peroxide radicals $\left(\mathrm{O}_{2}^{2-}\right.$ and $\mathrm{HO}_{2}^{-}$radicals). These radicals make ferrate a strong oxidizer and the ferric ion makes it a good coagulant. This toxin removal after a 30 min contact time was $93 \%$ at a ferrate dose of $20 \mathrm{mg} / \mathrm{l}, 98 \%$ at a dose of $40 \mathrm{mg} / \mathrm{l}$ as shown in Fig. 1. The results showed that microcystin-LR was easily decomposed by ferrate and that the decomposition depended on the ferrate dosage.

During the process of oxidation, ferrate was reduced to $\mathrm{Fe}^{3+}$ or $\mathrm{Fe}(\mathrm{OH})_{3}$ and then the flocculation was performed. After the formation of iron-colloid precipitates, the concentration of residual iron was $2.87 \mathrm{mg} / \mathrm{l}$ and the corresponding TOC removal was about $25 \%$ at the dosage of $20 \mathrm{mg} / \mathrm{l}$ $\mathrm{FeO}_{4}^{2-}$ as shown in Fig. 2. However at the dosage of $40 \mathrm{mg} / \mathrm{l} \mathrm{FeO}{ }_{4}^{2-}$, the flocculation enhanced and the most organic high molecular compounds in the blue extract were co-precipitated so that $50 \%$ TOC was eliminated. However, increasing the dosage of ferrate, the TOC removal remained invariable. So it is concluded that flocculation was ineffective for absorbing the middle molecular weight organics such as MCLR. Before treatment of ferrate, the $\mathrm{pH}$ of the blue extract was between 7.0 and 7.5, and after the ferrate oxidation the $\mathrm{pH}$ changed to 8.0-10.0.

\subsection{Effect of $p H$ on ferrate treatment to remove MCLR}

The effect of $\mathrm{pH}$ on ferrate oxidizing MCLR was determined as shown in Fig. 3. The pH values of toxin solution at a $40 \mathrm{mg} / \mathrm{l}$ ferrate were adjusted to 2, 4, 6, 7, 8, and 10 using $0.1 \mathrm{M}$ hydrochloric acid or sodium hydroxide. When $\mathrm{pH}$ is below 6 , the reaction speeds are very fast and the blue extract fades quickly, but the amount of toxin measured is 


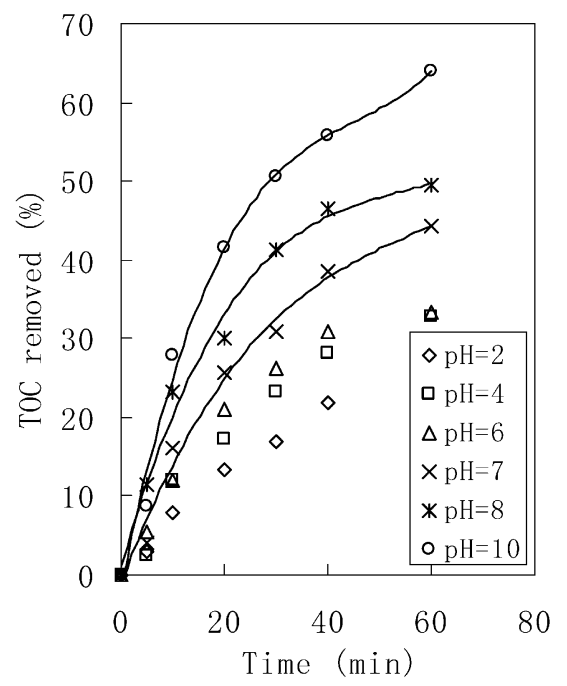

Fig. 4. TOC removal by ferrate oxidation-coagulation at different $\mathrm{pH}$.

removed ineffectively. The reason might be that ferrate decomposed itself rapidly to $\mathrm{Fe}^{3+}$ under such $\mathrm{pH}$ values. When $\mathrm{pH}$ range is $6-10$, a $40 \mathrm{mg} / \mathrm{l}$ ferrate dose gives a good toxin removal. So the $\mathrm{pH}$ mainly affected the flocculation process. When $\mathrm{pH}$ is below 6 , ferric ion coagulation was not evident so that the residual $\mathrm{Fe}$ and TOC value was relatively high. It corresponds to the characteristics of ferrate oxidation and coagulation when the residual iron is little and TOC removal is above $50 \%$.

\subsection{TOC removal by ferrate oxidation-coagulation}

High TOC values in blue extract, $40-50 \mathrm{mg} / 1$, were observed and the TOC removal at different dosages of ferrate and $\mathrm{pH}$ scale was studied (Figs. 2 and 4). Coagulation has the effect of removing higher molecular weight, easy-toflocculate the impurity in the blue extract (Bruchet et al., 1990). The generation of reduced product $\mathrm{Fe}^{3+}$ resulted in a more efficient formation of the iron-colloid precipitates, which could co-precipitate the organic compound and then the TOC decreased. For example, at the dosage of $40 \mathrm{mg} / \mathrm{l}$ $\mathrm{FeO}_{4}^{2-}$, most organic high molecular compounds in the blue extract were precipitated so that the TOC removal could be reached about $50 \%$. The optimum $\mathrm{pH}$ for coagulation was 6-10. But for lower-molecular weight organic compounds, the higher coagulant dosage was required and the lower TOC removal was obtained. Except for the higher molecular weight compound in the blue extract, the molecular weight distribution of dissolved organic carbon (DOC) from cyanobaterial water has been characterized as predominantly in the range of 1000-10 000 (Tuschall and Brezonik, 1980). So the removal of TOC could not be increased again although the dosage of ferrate had been increased to $200 \mathrm{mg} / \mathrm{l}$.

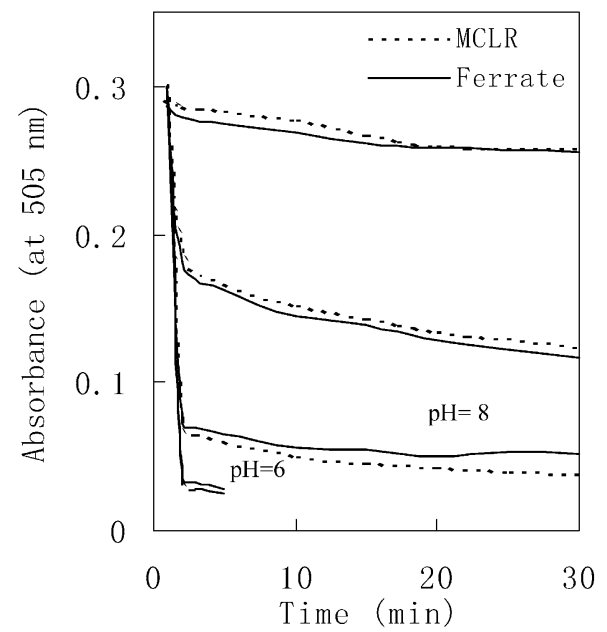

Fig. 5. Decomposition of ferrate in the presence of microcystin-LR at $\mathrm{pH} 6-10$.

\subsection{The mechanism of microcystin-LR removal by ferrate treatment}

Through monitoring spectrophotometrically the ferrate decomposition (at $505 \mathrm{~nm}$ ) in the presence of microcystinLR, the mechanism of the microcystin-LR removal by ferrate are discussed. Fig. 5 shows that microcystin-LR had no effect on the normal ferrate decomposition over a $\mathrm{pH}$ range of 6-10. However, it was later determined by liquid chromatographic studies that most of microcystinLR was oxidized by ferrate (Fig. 6). It was postulated that ferrate reacts with microcystin-LR through a stable intermediate such as intermediate oxidizing species (which is a lower oxidation state of iron). The reaction between microcystin-LR and ferrate results in the ultimate precipitation of an iron +3 hydroxide in the contents of the reaction vessels.

In order to observe the ferrate effect on microcystin-LR in detail, a preliminary assessment of the structural changes was performed after ferrate oxidation at a dose of $20 \mathrm{mg} / \mathrm{l}$. After $1 \mathrm{~h}$ contact time, microcystin-LR was structurally destroyed and two new peaks appeared with a retention time of $7 \mathrm{~min}$ (Fig. 6). The wavelength of $238 \mathrm{~nm}$ detects the aromatic portion of the Adda side chain, and the wavelength of $210 \mathrm{~nm}$ detects the peptide bonds in the ring of MCLR. These results indicated that the chromatographic properties of MCLR had changed. The results also suggested that (a) the 'Adda' group was modified, resulting in a loss of absorbance at $238 \mathrm{~nm}$, and (b) the heptapeptide ring of MCLR has been opened or destroyed, resulting in a loss of absorbance at $210 \mathrm{~nm}$. Thus, MCLR appears to have been extensively removed after ferrate oxidation.

In summary, the results obtained indicate that ferrate oxidation-coagulation is a potential water treatment method for the destruction of peptide toxin produced by various species of cyanobacteria. The destruction of the peptide 


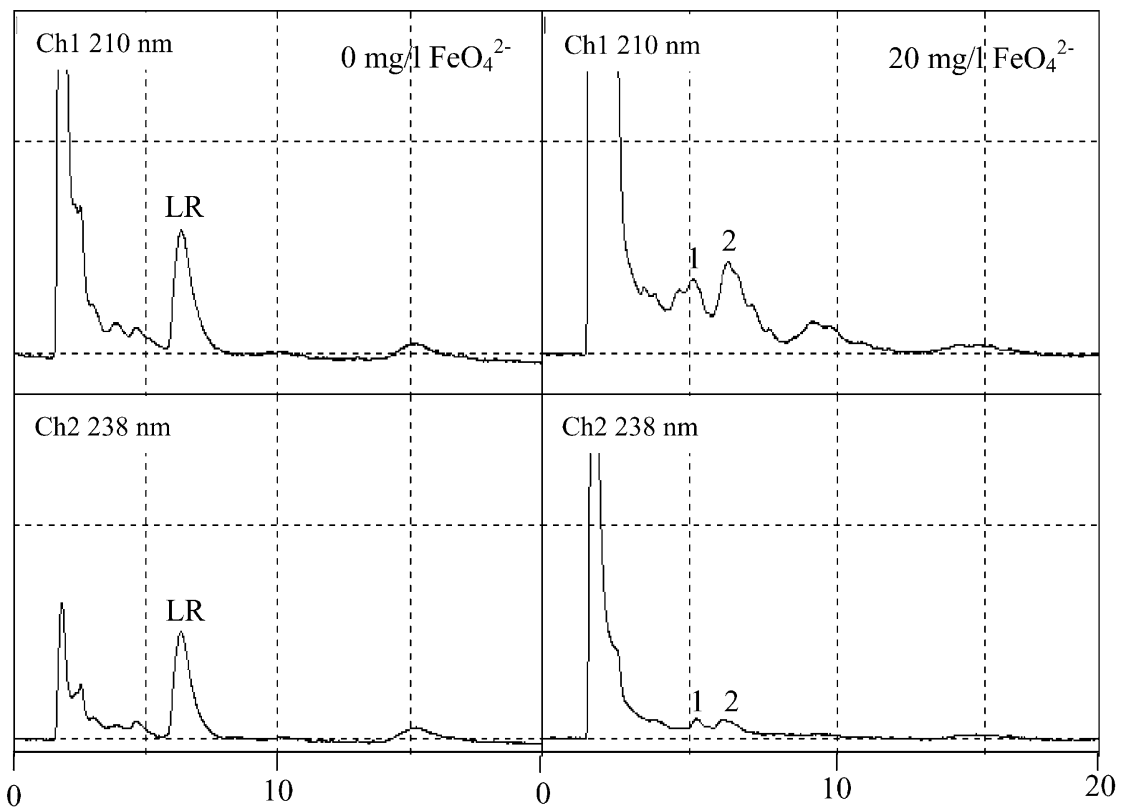

Fig. 6. HPLC chromatograms of microcystin-LR before and after ferrate treatment Column: Microsorb MV ${ }^{\mathrm{TM}} 5 \mathrm{C} 18(150 \times 4.6 \mathrm{~mm}) . \mathrm{Mobile}$ phase: acetonitrile-0.01 M ammonium acetate (pH 6.8). Flow rate: $1 \mathrm{ml} / \mathrm{min}$. Detection: 210 and $238 \mathrm{~nm}$. Microcystin-LR is abbreviated as LR. The reaction products are seen at peaks 1 and 2 .

toxin by ferrate is $\mathrm{pH}$ dependent and the toxin removal is effective at $\mathrm{pH}$ 6-10. For treating $200 \mathrm{mg}$ freezed-dried cyanobacteria, the dosage of ferrate $40 \mathrm{mg} / \mathrm{l}$ could be given above $100 \%$ toxin removal, and correspondingly, $\mathrm{Fe}(\mathrm{OH})_{3}$ flocculated organic materials in the blue extract and TOC removal reached approximate $50 \%$. Microcystin reacted with ferrate at the conjugated diene of Adda and the heptapeptide ring of MCLR to give two new intermediate products. From the results of HPLC, these products might be the stereoisomers and/or regioisomers of one another because the maximum absorbance wavelength shifted about $10 \mathrm{~nm}$ to UV area.

\section{Acknowledgements}

The authors are grateful to the National Science Foundation of China under research Grant No. 20077031 and Science and Practice Foundation of Chinese Academic Sciences (for postgraduate) to support this project.

\section{References}

Angeline, K.-Y.L., Phillip, M.F., Ellie, E.P., 1995. Biotransformation of the cyanobacterial hepatotoxin microcystin-LR, as determined by HPLC and protein phosphatase bioassay. Environ. Sci. Technol. 29, 242-246.

Bellar, T.A., Lichtenberg, J.J., Dromer, R.C., 1974. The occurrence of organohalides in chlorinated drinking waters. J. Am. Water Works Assoc. 68, 703-706.

Bruchet, A., Rousseau, C., Mallevialle, J., 1990. Pyrolysis GC-MS for investigating high molecular weight THM precursors and other refractory organics. J. Am. Works Assoc. 82, 66-74.

Codd, G.A., 1995. Cyanobacterial toxins: occurrence, properties and biological significance. Water Sci. Technol. 34, 149-156.

De Luca, S.J., Chao, A.C., Smallwood, C., 1983. Ames test of ferrate treated water. J. Environ. Engng Div. 109, 11591167.

Eriksson, J.E., Toivola, D., Meriluoto, J.A.O., Karaki, H.Y.G., Hartshome, D., 1990. Hepatocyte deformation induced by cyanobacterial toxins reflects inhibition of protein phosphatases. Biochem. Biophys. Res. Commun. 173, 1347-1352.

Gilbert, M.B., Waite, T.D., Harris, C., 1976. An investigation of the applicability of ferrate ion for disinfection. J. Am. Water Works Assoc. 68, 495-497.

Himberg, K., Keijola, A.M., Hiisvirta, L., Pyysalo, H., Sivonen, K., 1989. The effect of water treatment process on the removal of hepatotoxins from Microcystis and Oscillatoria cyanobacteria: a laboratory study. Water Res. 23, 979-984.

Kronberg, L., Vartiainen, T., 1988. Ames mutagenicity and concentration of the strong mutagen 3-chloro-4-(dichloromethyl)-5hydroxy-2 $(5 H)$-furanone and its geometric isomer $E$-2chloro-3-(dichloromethyl)-4-oxo-butenoic acid in chlorine-treated tap water. Mutat. Res. 206, 177-182.

Lambert, T.W., Holmes, C.F.B., Hrudey, S.E., 1996. Adsorption of Microcystin-LR by activated carbon and removal in full scale water treatment. Water Res. 30, 1411-1422.

Rositano, J., Nicholson, B.C., Pieronne, P., 1998. Destruction of cyanobacterial toxins by ozone. Ozone: Sci. Engng 20, 223238 . 
Schreyer, J.M., Thompson, G.W., Ockerman, L.T., 1953. Inorganic Synthesis. McGraw-Hill, New York.

Sivonen, K., Niemelä, S.I., Niemi, R.M., Lepistö, L., Luoma, T.H., Räsänen, L.A., 1990. Toxic cyanobacteria (blue green algae) in Finnish fresh and coastal waters. Hydrobiologia 190, 267-275.
Tuschall, J.R., Brezonik, P.L., 1980. Characterization of organic nitrogen in natural waters: its molecular size, protein content, and interactions with heavy metals. Limnol. Oceanogr. 25, 495504. 